\title{
Neuroendocrine tumor of anal canal
}

INSERM

\section{Source}

INSERM. (1999). Orphanet: an online rare disease and orphan drug data base.

Neuroendocrine tumor of anal canal. ORPHA:100082

Neuroendocrine tumor of the anal canal is an epithelial tumor of anal canal arising from enterochromaffin cells in the colorectal-type epithelium above the dentate line and in the anal transition zone. The tumors are slow growing and the majority of cases are diagnosed in later advanced stages. It may present with symptoms related to the anatomical location of the tumor (rectal mass, rectal bleeding and pain, tenesmus or changes in bowel habits), symptoms of carcinoid syndrome (flushing and increased gut motility) or nonspecific symptoms of advanced disease (hepatomegaly, fever, weight loss, anorexia, malaise). 